\title{
Aconselhamento em amamentação durante o puerpério pelo Cirurgião-Dentista:
}

\section{Uma revisão}

\author{
Counselling on breastfeeding during the puerperium by the Dentist: A review \\ Asesoramiento sobre la lactancia durante el puerpério por el Dentista: Una revisión
}

Recebido: 25/05/2021 | Revisado: 31/05/2021 | Aceito: 03/06/2021 | Publicado: 18/06/2021

Andressa Adelseck da Costa

ORCID: https://orcid.org/0000-0001-6302-0509

Centro Universitário Maurício de Nassau, Brasil

E-mail: andressadelseck@gmail.com

Nilton José da Silva Filho

ORCID: https://orcid.org/0000-0001-5802-8362

Universidade Federal de Pernambuco, Brasil

E-mail: niltonjfh@gmail.com

Brunelle Costa da Silva

ORCID: https://orcid.org/0000-0003-1684-370X

Universidade Federal de Pernambuco, Brasil

E-mail: brunellec01@gmail.com

Isabela Janne de Lima

ORCID: https://orcid.org/0000-0001-5123-9837

Universidade Federal de Pernambuco, Brasil E-mail: ijlbio@hotmail.com

Maria Eduarda Sabino

ORCID: https://orcid.org/0000-0002-4649-9586

Faculdade de Odontologia de Recife, Brasil

E-mail: mariaeduardabosabino@gmail.com

Diego Belmiro do Nascimento Santos

ORCID: https://orcid.org/0000-0002-0109-6863

Secretaria Municipal de Saúde do Rio de Janeiro, Brasil

E-mail: diegobelmiro@outlook.com

Samuel Rodrigo de Andrade Veras

ORCID: https://orcid.org/0000-0002-9426-2532 Instituto de Medicina Integral Professor Fernando Figueira, Brasil E-mail: Samuel_dsa@hotmail.com

\begin{abstract}
Resumo
Este trabalho trata-se de uma revisão de literatura abordando os principais tópicos sobre a amamentação. Foi realizada uma busca de estudos disponíveis nas bases de dados eletrônicos, com os descritores previamente selecionados. Através da pesquisa foi possível observar que o aleitamento materno tem muitas vantagens para o desenvolvimento e crescimento do bebê, além de inúmeros benefícios para as mães. Essa revisão aborda a técnica adequada de amamentação e as orientações que o cirurgião dentista deve fazer para evitar o desmame precoce. A falta de informação das mães faz com que elas se sintam inseguras quando se fala de amamentar seu filho, o cirurgião dentista deve estar capacitado para acolher e dar apoio desde o pré-natal até o tempo que for preciso. É de extrema importância a orientação sobre o aleitamento em tempos de COVID-19, o profissional deve assegurar para as mães que os benefícios do aleitamento materno exclusivo até os 6 meses de idade é de fundamental importância para o recémnascido, e que mesmo a mãe estando infectada pelo vírus, ainda assim é aconselhado amamentar seu filho.
\end{abstract}

Palavras-chave: Amamentação; Aleitamento materno exclusivo; Recém-nascido.

\begin{abstract}
This study is a review of the literature addressing the main topics on breastfeeding. The search for available studies took place in the electronic databases, based on previously selected keywords. It was possible to observe that breastfeeding has many advantages for the development and growth of the baby, in addition to numerous benefits for their mothers. This review addresses the proper breastfeeding technique and the guidelines that the dentist must follow to avoid early weaning. The mothers' lack of information makes themselves to feel insecure when talking about breastfeeding their child, the dentist must be able to welcome and support since the prenatal period until the time it is necessary. It is extremely important to provide guidance on breastfeeding in times of COVID-19, the professional must ensure for mothers that the benefits of exclusive breastfeeding up to 6 months of age are fundamental for the newborn, and that even if the mother is infected by the virus, it is still advisable to breastfeed her child.
\end{abstract}

Keywords: Breastfeeding; Exclusive breastfeeding; Newborn. 


\begin{abstract}
Resumen
Este trabajo consiste en una revisión de literatura, abordando los principales tópicos sobre el amamantamiento. Fue realizada una búsqueda de estudios disponibles en las bases de datos electrónicos, con los descriptores previamente seleccionados. A través de la búsqueda fue posible observar que el amamantamiento materno tiene muchas ventajas para el desenvolvimiento y crecimiento del bebé, además de innumerables beneficios para las mamás. Esta revisión aborda la técnica adecuada de amamantar y las orientaciones que el dentista cirujano debe hacer para evitar el destete precoz. La falta de información de las mamás hacen que se sientan inseguras cuando se habla de amamantar su hijo, el dentista cirujano tiene que estar capacitado para acompañar y dar apoyo desde el pre-natal hasta el tiempo que sea necesario. Es de extrema importancia la orientación sobre el amamantamiento en tiempos de COVID-19. El profesional debe asegurar a las mamás que los beneficios de amamantar hasta los 6 meses de edad es de vital importancia para los recién nacidos, y que aún que la madre esté infectada por el virus, es aconsejable amamantar a su hijo.
\end{abstract}

Palabras clave: Amamantamiento; Amamantamiento exclusivo; Recién nacido.

\title{
1. Introdução
}

O leite materno é o principal alimento do bebê durante seus primeiros meses de vida devido à variedade de nutrientes essenciais que o constitui. Estão presentes em sua composição diversas vitaminas, proteínas, carboidratos, gordura, sais minerais e água. Todos esses componentes são fundamentais para o desenvolvimento, crescimento e prevenção de doenças no lactente (Moraes, Oliveira \& Dalmas, 2013). Além disso, o aleitamento materno é vital não só para a saúde e desenvolvimentos das crianças, estando também associado a redução dos custos nos sistemas de saúde, nas famílias e para os governos (Araujo, et al., 2014).

A Organização Mundial da Saúde (OMS) e o Ministério da Saúde (MS) recomendam o aleitamento materno como forma exclusiva de alimentação até os seis meses de idade e, de maneira completar, até os dois anos, devendo ter seu o início nos primeiros 60 minutos de vida (Ministério da Saúde, 2009).

Diversos benefícios estão relacionados à amamentação como redução da incidência de diarreias, doenças respiratórias, obesidade, otites na criança e melhor desenvolvimento da oclusão (Abaté et al., 2020). Além disso, aumenta o vínculo mãefilho e tem relação com redução de peso, prevenção do câncer de mama e menores gastos financeiros para a mãe. Devido a importância da amamentação, observou-se uma necessidade de abordagem do tema durante as consultas de pré-natal, uma vez que, quanto maior o contato com o assunto, maior o esclarecimento e aprendizado (Almeida, Luz \& Ued, 2015).

Durante o período de puerpério é importante não só a orientação de técnicas, mas também o manejo das dificuldades apresentadas durante a amamentação pela puérpera (Almeida, Luz \& Ued, 2015). Nesse contexto, o trabalho desenvolvido pelo Cirurgião-Dentista (CD) durante as consultas de pré-natal e puerpério são importantes para o estímulo e estabelecimento da amamentação (Moraes, Oliveira \& Dalmas, 2013). Segundo Giugliani (2004), durante estas consultas, o profissional deve estar apto a orientar, incentivar, apoiar e encorajar as puérperas a respeito da importância e os benefícios do aleitamento materno para seus recém-nascidos, desde suas primeiras horas de vida até seus 24 meses.

Dessa maneira, se faz importante o conhecimento de técnicas de amamentação, bem como no tocante aos principais problemas decorrentes da amamentação, como traumas mamários, ingurgitamento mamário e mastite por parte do CD. O adequado manejo dessas situações pode prevenir o desmame precoce e estabelecer um vínculo de confiança com a mãe, atuando não só no puerpério, mas durante todas as fases de desenvolvimento da criança (Giugliani, 2004).

Diante da importância do tema proposto, buscou-se através deste trabalho, revisar a literatura sobre os principais tópicos relacionados à amamentação e que devem ser abordados pelo cirurgião-dentista durante as consultas de puerpério.

\section{Metodologia}

Este estudo foi realizado através da busca sistematizada da literatura científica nas bases de dados MEDLINE (Literatura Internacional em Ciências da Saúde), LILACS (Literatura Latino- Americana e do Caribe em Ciências da Saúde, 
SCIELO (Scientific Electronic Library Online). Para esta pesquisa não houve a utilização de limites temporais.

Como estratégia de busca, foram utilizados os seguintes descritores em português e em inglês: "aleitamento materno", "amamentação", "Alimentação ao Peito" "Recém-Nascido", "breast feeding", "Newborn", "infant". Estes descritores foram escolhidos com base em uma consulta prévia à literatura, visando averiguar quais descritores eram relacionados ao tema de estudo. Os critérios de busca foram aplicados para os títulos e resumos. Foram considerados os artigos publicados em português e/ou inglês. Após a leitura dos títulos e resumos foram excluídos os estudos não relacionados ao tema e os artigos em duplicidade nas bases de dados.

\section{Revisão de Literatura}

No final da revolução industrial, o uso do leite artificial teve um grande aumento, enquanto que o aleitamento materno uma redução. Isso ocorreu porque o marketing da indústria influenciava o consumo do leite artificial. A partir de 1981 surgiu o Programa Nacional de Incentivo ao Aleitamento Materno (PNIAM), que implementou políticas públicas de promoção e apoio ao leite materno no Brasil (Venancio \& Monteiro, 1998).

A prevalência e duração do aleitamento materno exclusivo aumentaram em todos as regiões do Brasil entre as décadas de 1990 e 2010. Parte dessa tendência pode ser atribuída às políticas nacionais de promoção, proteção e apoio ao aleitamento materno (Boccolini, Carvalho \& Oliveira, 2015).

\subsection{Tipos de aleitamento materno}

A Organização Mundial de Saúde (OMS) classifica o aleitamento em cinco tipos. Cada um deles difere entre si pelo uso ou não de complemento que é feito e pela fonte do leite ofertado a criança (Ministério da Saúde, 2009).

No aleitamento materno exclusivo as crianças obtêm o leite materno diretamente da nutriz ou de outras fontes. Nesse tipo não há oferta de outros líquidos ou sólidos, exceto gotas ou xaropes, contendo suplementos vitamínicos, minerais ou medicamentos. No aleitamento materno predominante as crianças além de receberem leite materno, fazem uso de outros líquidos como, por exemplo, água e sucos. No aleitamento materno, o bebê recebe leite materno direto do peito ou ordenhado e oferecido em copo, xícara ou colher. Quando a criança recebe outros tipos de alimentos sólidos ou semi-sólidos, além do leite materno, esse tipo de aleitamento passa a ser considerado como complementado. Nesses casos, os alimentos oferecidos são para complementar o aleitamento e não substituí-lo. Por fim, existe ainda o tipo de aleitamento materno misto ou parcial que ocorre quando é oferecido à criança qualquer outro tipo de leite, incluindo o leite materno (Ministério da Saúde, 2009).

\subsection{Importância do aleitamento materno}

O leite materno é de fundamental importância para saúde do bebê, pois contém nutrientes importantes para o crescimento e desenvolvimento da criança. O primeiro leite, conhecido como colostro, é considerado como a primeira vacina do recém-nascido uma vez que possui substâncias de proteção como anticorpos e outros nutrientes essenciais para manutenção da saúde do bebê (Boccolini, Carvalho \& Oliveira, 2015).

Além disso, fatores econômicos também são postos como vantagens. Em países em desenvolvimento, para algumas famílias, a amamentação é uma fonte de economia, visto que a maioria da população é desfavorecida economicamente. Dessa maneira, pode-se afirmar que além dos benefícios para o recém-nascido em termos de qualidade de vida, o aleitamento materno também beneficia a família e o governo, visto que as crianças que mamam precisam de menos cuidados médicos, hospitalização e medicamentos (Moraes, Oliveira \& Dalmas, 2013).

De acordo com Boccolini (2012), um estudo realizado em Gana, com uma amostra de cerca de 11 mil crianças, chegou a conclusão que $22 \%$ das mortes neonatais poderiam ter sido evitadas se todas as crianças tivessem sido amamentadas 
nas primeiras horas de vida. Garcia et al., (2011) observou que o início do aleitamento tardio (superior a 24 horas), estava associado a um aumento de 78\% do risco de mortalidade neonatal na Índia. Dessa forma, os mecanismos que podem justificar a proteção que a amamentação na primeira hora de vida proporciona para a redução da mortalidade neonatal estão relacionados aos elementos imunológicos e probióticos do leite materno, e seu papel ativo na imunidade do bebê (Boccolini, 2012).

$\mathrm{O}$ leite materno apresenta nutrientes específicos para atender às necessidades das crianças durante o crescimento $\mathrm{e}$ contém substâncias imunológicas da mãe para proteger os filhos de doenças infecciosas e diarréicas (Unicef, 2019). Durante os primeiros meses de vida a qualidade dos lipídios fornecidos pelo leite materno pode determinar não só o crescimento e desenvolvimento de uma criança, mas também a resposta imune desta para doenças infecciosas e a prevenção de doenças em adultos. As dietas das lactantes devem conter quantidades suficientes de ácidos graxos poliinsaturados de cadeia longa (AGPICL) para atender às necessidades de gestantes e bebês e prevenir alergias e infecções (Silva, Schneider \& Stein, 2009).

No que diz respeito à proteção do sistema gastrointestinal, a literatura mostra que bebês amamentados por 6 meses ou mais podem reduzir de forma significativa o número de infecções intestinais, quando comparado a bebês que não foram amamentados. Nos países em desenvolvimento, há um grande número de bebês sem acesso ao aleitamento materno exclusivo e a falta de aleitamento materno em crianças de 6 a 23 meses pode estar associada ao aumento da morbimortalidade por diarreia, apontando que o aleitamento materno tem um efeito preventivo na morbimortalidade de diarreia em crianças de 0 a 23 meses (Lamberti, et al., 2011).

Com relação aos benefícios à longo prazo, estudos apontam para redução da pressão arterial e do colesterol total, melhores resultados em testes de inteligência, menor sobrepeso e obesidade e menor chance de desenvolvimento de diabetes tipo 2 (Menezes, 2018). Um estudo mostrou que até o sexto mês após o nascimento, a incidência de sobrepeso e obesidade em crianças amamentadas reduz. Dessa maneira, destaca-se que amamentação é um fator de proteção para impedir que as crianças desenvolvam um excesso de peso (Silva, Venâncio \& Marchioni, 2010; Moraes \& Giugliano, 2011).

Até os seis meses de idade o leite materno pode atender às necessidades de ferro dos bebês, após esse período é necessário suprir essa nutrição complementando com alimentos. Entretanto, a substituição do leite materno por leite fresco ou pasteurizado pode trazer algumas consequências, uma vez que a composição do leite de vaca é diferente do leite humano, fornecendo elevados valores de proteína e minerais que podem interferir na absorção de ferro e consequentemente predispor um quadro de anemia (Osório, Lira \& Ashworth, 2004). A amamentação e a alimentação assistida saudável, quando usadas em combinação com outras medidas, desempenham um papel importante na prevenção da deficiência de ferro. Essas práticas podem ser bem-sucedidas por meio de ações efetivas de profissionais de saúde (Bortolini \& Vitolo, 2010).

A amamentação também apresenta papel crucial no desenvolvimento do sistema estomatognático. $\mathrm{O}$ ato da sucção envolve desde a sensibilidade do bebê ao sentir com os lábios o mamilo da mãe até o momento de deglutição do leite materno. O seio materno funciona como aparelho ortodôntico natural, pois ao sugar o bebê posiciona a língua adequadamente e outras estruturas também movimentam-se harmoniosamente, favorecendo o desenvolvimento (Bervian, Fontana \& Caus, 2010). Sendo assim, a amamentação tem papel importante no desenvolvimento adequado dos órgãos fonoarticulatórios como musculatura oral e arcadas dentárias quanto à mobilidade, força, postura, e desenvolvimento da respiração, mastigação, deglutição e articulação dos sons da fala (Neiva, et al., 2003).

Para que haja um aleitamento eficaz é necessário que o bebê esvazie os seios lactíferos, necessitando da introdução da maior parte da aréola na boca. Esse mecanismo pode se tornar prejudicado nos bebês com fissura de lábio e/ou palato, nesses casos a amamentação terá uma duração maior podendo ser necessária a oferta em mamadeira com bicos macios de látex e furo ligeiramente aumentado. Salienta-se também a importância da amamentação com o bebê mais ereto e ao lado da fissura, visando um maior estímulo da musculatura (Ninno, et al., 2011). 
As mães também são beneficiadas pelo ato de amamentar. Benefícios como redução do risco de câncer de mama e ovário, da incidência de fraturas de quadril por osteoporose, menor chance de nova gravidez e diminuição de peso pós-parto podem ser apontados (Rea, 2004).

\subsection{Amamentação e desenvolvimento craniofacial}

A amamentação pode ser descrita como um dispositivo ortopédico natural, que promove um bom desenvolvimento craniofacial através dos movimentos realizados pela língua e mandíbula, durante a sucção do leite materno, estimulando um melhor crescimento da maxila e mandíbula (Boronat-Catalá et al., 2019; Da Rosa et al 2020). O ato de amamentar está, de forma positiva, relacionado ao desenvolvimento das arcadas dentárias na dentição decídua nos planos transverso anterior e sagital (Abaté et al., 2020). Sánchez et al (2010) realizaram um estudo onde observaram radiográficas laterais de crânio de 197 pacientes e observaram que as crianças que foram amamentadas apresentavam uma relação correta do plano sagital e vertical da mandíbula em relação à maxila e à base do crânio.

Em um estudo por De Ferrer e Varela (2006), 290 crianças de 5 anos de idade foram divididas em dois grupos, os que receberam amamentação natural nos primeiros meses de vida, e os que só receberam amamentação artificial. Como resultado, a maior porcentagem de crianças com uma oclusão normal estava no grupo que recebeu amamentação natural (Boronat-Catalá et al., 2019).

Além disso, para a criança obter o leito materno, é necessário um grande estímulo da língua e músculos peri-orais. Em contrapartida, exige-se menos esforço quando se utiliza de amamentação artificial com mamadeiras, portanto, causando menos estímulo nas estruturas orofaciais. Dessa forma, o aleitamento natural pode promover um melhor desenvolvimento das estruturas orofaciais (Boronat-Catalá et al., 2019).

\subsection{Técnica adequada de amamentação}

Sabe-se que o posicionamento adequado entre mãe e bebê, bem como uma pega correta do peito, favorecem o aleitamento materno exclusivo. Em uma técnica adequada de amamentação a mãe deve estar confortável e bem apoiada de maneira que o corpo da criança fique de frente para a mãe na posição "barriga para barriga", com as nádegas firmes, apoiadas pelas mãos da mãe. Além disso, a cabeça da criança deve estar no mesmo nível da mama, com o nariz no nível do mamilo e o queixo tocando na mama (Ministério da Saúde, 2009).

\subsection{Problemas relacionados à amamentação e como manejá-los}

As complicações mamárias são consideradas uma das principais razões para a interrupção precoce do aleitamento materno devido à dor e desconforto enfrentados pelas mães, principalmente nas primíparas (Lima, Nascimento \& Martins, 2018). Dessa maneira, é importante o conhecimento do Cirurgião-Dentista a respeito das situações mais comuns que possam ocorrer para prevenir, orientar e encaminhar, quando necessário, evitando que quadros mais simples evoluem para complicações graves. Esse cuidado do profissional é importante para que a amamentação não seja um problema, como em casos de mamilos planos ou invertidos. Nessas situações, quando não há orientação e manejo profissional, é comum o abandono da amamentação devido às dificuldades encontradas pela mãe, bem como pela falta de apoio e incentivo familiar e profissional (Silva, et al., 2011). Para corrigir esse problema recomenda-se o uso de uma técnica que indique ação inspiratória e que possa ser aplicada antes e durante o intervalo de amamentação. Utiliza-se uma seringa de 10 ou $20 \mathrm{ml}$ e faz-se a sucção do mamilo por 30 a 60 segundos (Ministério da Saúde, 2009).

Outro problema identificado em algumas mulheres é o ingurgitamento mamário decorrente de diversos fatores, como a introdução de amamentação tardia, técnicas inadequadas de amamentação, esvaziamento inadequado ou pouco frequente, 
restrições no tempo de amamentação, aumento da produção de leite e sucção ineficaz dos bebês. É importante o reconhecimento dessa complicação o quanto antes para evitar o desenvolvimento de problemas como mastite e abscessos mamários A orientação dada à mãe é de continuidade da amamentação, visto que a interrupção pode agravar o quadro. Massagem circular nas mamas antes da amamentação pode contribuir para amolecer a mama, além de promover a aderência do bebê e facilitar a ordenha (Oliveira, et al., 2015).

A mastite é definida como inflamação de uma ou mais partes da mama que podem ou não evoluir para uma infecção bacteriana. Fatores que podem estar relacionados a esta condição são a obstrução do ducto mamário e falta de tratamento, congestão da glândula mamária, esvaziamento incompleto da mama, baixa resistência à infecção, fadiga, estresse psicológico, interrupção súbita da amamentação, uso de chupetas e mamadeiras e sucção fraca de recém-nascidos (Mass, 2004). O tratamento deste problema deve ser o mais rápido possível e é de extrema importância o apoio emocional dos profissionais de saúde e familiares. Deve-se orientar uma consulta com o médico, mas no geral está indicado o esvaziamento completo da mama afetada através da amamentação ou ordenha manual. Em alguns casos, é necessário o uso de medicamentos sob orientação médica, como analgésicos fracos para aliviar a dor e antibióticos no tratamento de infecções (Fetherston, 1998). Quando não se intervém de forma precoce e efetiva, a mastite pode evoluir para um abscesso mamário. O diagnóstico é baseado em parâmetros clínicos como dor intensa, desconforto, calafrios, aumento da temperatura corporal e flutuações na palpação da área afetada, geralmente é unilateral (Mannel, Martens \& Walker, 2013).

A candidíase é outra patologia que pode acometer a mama, sendo uma infecção fúngica comum no mamilo no período pós-parto. Geralmente, as mães infectadas relatam prurido, sensação de queimação e formigamento nos mamilos que permanecem após a amamentação. O bebê, por sua vez, muitas vezes é assintomático. Quando há necessidade de intervenção, mãe e bebê devem ser tratados concomitantemente. Incialmente o tratamento é local, mas se não houver melhorar do quadro pode haver necessidade de tratamento sistêmico. Outros cuidados adicionais que devem ser repassados incluem higiene pessoal adequada, substituição de sutiãs diariamente, enxágue e secagem dos mamilos após a amamentação e exposição à luz solar (Tanguay, Mcbean \& Jain, 1994).

Além disso, é importante destacar que existe um número limitado de doenças infecciosas maternas que podem contraindicar a amamentação, como no caso da infecção pelo HIV-1 e HIV-2 (em países como o Brasil) e pelo HTLV-1 e HTLV-2. Em outras patologias infecciosas, intervenções preventivas podem ser tomadas a fim de garantir a manutenção do aleitamento materno, como o uso de imunoglobulina sérica, vacinação ou até medicação antimicrobiana profilática.

\subsection{Amamentação em tempos de pandemia do covid-19}

Considerando os benefícios da amamentação para a saúde da criança e da mulher e a ausência de evidências científicas sobre a transmissão viral por meio da amamentação, não há indicação de suspensão do aleitamento materno. Sendo assim, recomenda-se que a amamentação seja mantida mesmo em caso de infecção pelo COVID-19, desde que a mãe deseje amamentar e esteja em condições clínicas adequadas (Saps, 2020).

Dada à realidade de que as mães infectadas pelo coronavírus provavelmente já colonizaram seus bebês, a amamentação continuada pode ter potencial de transmitir anticorpos maternos protetores ao bebê através do leite materno (Liebert, 2020). Nesses casos, medidas preventivas podem ser tomadas, como lavar as mãos antes de amamentar e tocar no bebê, além do uso de máscara ao amamentar (Chen, et al., 2020; Wang, et al., 2020).

Se a mãe não se sentir confortável em amamentar a criança diretamente, a mesma pode fazer a retirada do leite manualmente ou usando bomba de extrair leite e delegar a função a outra pessoa que esteja saudável para dar o leite ao bebê através de copo, xícara ou colher (Liebert, 2020). 
Todas as mães devem receber apoio prático para que possam iniciar, estabelecer e aprender a lidar com as dificuldades comuns da amamentação, incluindo medidas para controlar e prevenir a infecções (Amounier, Moulin \& Xavier, 2004; Miranda et al., 2020).

\section{Conclusão}

O sucesso da amamentação requer uma rede de apoio e todas as pessoas relacionadas à mãe e bebê devem estar cientes da sua importância, uma vez que a amamentação exclusiva até os seis meses de idade traz benefícios para o bebê e a mãe, como prevenção do câncer de mama, perda de peso da mãe, melhor qualidade de vida, melhor custo benefício, maior vínculo entre mãe e filho, menor risco de alergias, infecções respiratórias, infecções gastrintestinais, diarreia, diabetes, hipertensão, obesidade, prevenção da mortalidade infantil e anemia. Além disso, a sucção do seio da mãe estimula o crescimento e desenvolvimento ósseo.

Através desta revisão bibliográfica, ficou clara a importância da intervenção precisa para evitar o desmame precoce e auxiliar as mães na adoção de técnicas adequadas para redução do trauma mamilar e hábitos deletérios. Os dentistas devem ser responsáveis pela garantia da informação, esclarecimento de eventuais dúvidas e entendimento de problemas que as mães e suas famílias possam ter, a fim de garantir maior adesão da amamentação, contribuindo no desenvolvimento da criança.

\section{Referências}

De Moraes, P. S., De Oliveira, M. M. B., \& Dalmas, J. C. (2013). Perfil calórico do leite pasteurizado no banco de leite humano de um hospital escola. Revista Paulista de Pediatria, 46-50.

Boronat-Catalá, M., Bellot-Arcís, C., Montiel-Company, J. M., Almerich-Silla, J. M., \& Catalá-Pizarro, M. (2019). Does breastfeeding have a long-term positive effect on dental occlusion? Journal of clinical and experimental dentistry, 11(10), e947-e951. /10.4317/jced.56312

Da Rosa, D. P., Bonow, M. L. M., Goettems, M. L. G.,Damarco, F. F., Santos, I. S., Matijasevich, A., Barros, A. J., \& Peres, K. G. (2019). The influence of breastfeeding and pacifier use on the association between preterm birth and primary-dentition malocclusion: A population-based birth cohort study, American Journal of Orthodontics and Dentofacial Orthopedics, 754-763. /10.1016/j.ajodo.2019.06.014.

De Araújo, M. F. M., Del Fiaco, A., Pimentel, L. S., \& Schmitz, B. A. S. (2004). Custo e economia da prática do aleitamento materno para a familia. Rev. Bras. Saúde Matern. Infant, 135-141.

de Ferrer, A. L., \& de Villalba, T. B. V. (2006). Effect of the suction-swallowing action on orofacial development and growth. Rev. Fac. Cien. Med. Univ. Nac. Cordoba. 33-37.

Secretaria de Atenção à Saúde. Departamento de Atenção Básica. Saúde da criança: nutrição infantil: aleitamento materno e alimentação complementar. Caderno de Atenção Básica, Brasília: Ministério da Saúde, 2009; 23

De Almeida, J. M., Luz, S. A. B., \& Ued, F. V. (2015). Apoio ao aleitamento materno pelos profissionais de saúde: revisão integrativa da literatura. Revista Paulista de Pediatria, 355-362. 10.1016/j.rpped.2014.10.002.

Giugliani, E. R. J. (2004). Problemas comuns na lactação e seu manejo. Jornal de Pediatria, 147-154.

Venancio, S. I., \& Monteiro, C. A.(1998). A tendência da prática da amamentação no Brasil nas décadas de 70 e 80. Rev. Bras. Epidemiol. Rev. Bras. Epidemiol, 40-49.

Boccolini, C. S., De Carvalho, M. L., \& De Oliveira, M. I. C.(2015). Factors associated with exclusive breastfeeding in the first six months of life in Brazil: a systematic review. Revista de Saúde Pública, 1-16. http://dx.doi.org/10.1590/s0034-8910.2015049005971.

Ramos, C. V., De Almeida, J. A. G., Saldiva, S. R. D. M., Pereira, L. M. R., Alberto, N. S. M. C., Teles, J. B. M., \& Pereira, T. G. (2010). Prevalência do Aleitamento Materno Exclusivo e os fatores a ele associados em crianças nascidas nos Hospitais Amigos da Criança de Teresina - Piauí. Epidemiologia e Serviços de Saúde, 19(2), 115-124. https://dx.doi.org/10.5123/S1679-49742010000200004

Boccolini, C. S. (2012). Aleitamento materno: determinantes sociais e repercussões na saúde infantil. Rio de Janeiro, Fiocruz.

Unicef. (2019). Apenas 40\% das crianças no mundo recebem amamentação exclusiva no início da vida. World Health Organization.

Da Silva, D. R. N., Schneider, A. P., \& Stein, R. T. (2009). O papel do aleitamento materno no desenvolvimento de alergias respiratórias. Scientia Medica, 3543.

Lamberti, L. M., Walker, C. L. F., Noiman, A., Victora, C., \& Black, R. (2011). Breastfeeding and the risk for diarrhea morbidity and mortality. Bmc Public Health, 15-24. /10.1186/1471-2458-11-s3-s15. 
De Menezes, C. B. (2018). Beneficios do aleitamento materno exclusive até os seis meses de vida. (Tese de Doutorado) - Curso de Especialização em Saúde da Família, Unilab, São Francisco do Conde.

Silva, L. M. P., Venâncio, S. I., \& Marchioni, D. M. L. (2010). Práticas de alimentação complementar no primeiro ano de vida e fatores associados. Revista de Nutrição, 983-992, /10.1590/s1415-52732010000600005.

Moraes, J. F. V. N., \& Giugliano, R. (2011). Aleitamento materno exclusivo e adiposidade. Revista Paulista de Pediatria, 152-156. /10.1590/s010305822011000200004 .

Osório, M. M., Lira, P. I. C., \& Ashworth, A. (2004). Factors associated with Hb concentration in children aged 6-59 months in the State of Pernambuco, Brazil. British Journal Of Nutrition, 307-314. /10.1079/bjn20031042.

Bortolini, G. A., \& Vitolo, M. R. (2010). Importância das práticas alimentares no primeiro ano de vida na prevenção da deficiência de ferro. Revista de Nutrição, 1051-1062. /10.1590/s1415-52732010000600011.

Bervian, J., Fontana, M., \& Caus, B. (2010). Relação entre amamentação, desenvolvimento motor bucal e hábitos bucais - revisão de literatura. Revista da Faculdade de Odontologia - UPF.

Neiva, F. C. B., Cattoni, D. M., Ramos, J. L. A., \& Issler, H. (2003). Desmame precoce: implicações para o desenvolvimento motor-oral. Jornal de Pediatria, 1-7. /10.1590/s0021-75572003000100004.

Di NINNO, C. Q. M. S., Moura, D., Machado, S. V., Raciff, R., Rocha, C. M. G.; Norton, R. C., Martins, F. A. D., \& Britto, D. B. O. (2011). Aleitamento materno exclusivo em bebês com fissura de lábio e/ou palato. Rev Soc Bras Fonoaudiol, 417-421.

Rea, M. F. (2004). Os benefícios da amamentação para a saúde da mulher. Jornal de Pediatria, 1-7. /10.1590/s0021-75572004000700005.

Lima, A. P. C., Nascimento, D. S., \& Martins, M. M. F. (2018). A prática do aleitamento materno e os fatores que levam ao desmame precoce: uma revisão integrativa. J. Health Biol Sci., 189-196.

Silva, L. D., Da Silva, K. V., Lea, L. P., \& Avcrski, M. (2011). Técnica de amamentação: Preparo das nutrizes atendidas em um hospital escolar, RecifePE. Rev Rene Fortaleza, 121-127.

De Oliveira, C. S., Iocca, F. A., Carrijo, M. L. R., \& Garcia, R. A. T. M. (2015). Amamentação e as intercorrências que contribuem para o desmame precoce. Revista Gaúcha de Enfermagem, 16-23. /10.1590/1983-1447.2015.esp.56766.

Mass, S. (2004). Breast Pain: engorgement, nipple pain and mastitis. Clinical Obstetrics And Gynecology, 676-682. /10.1097/01.grf.0000135652.49154.75.

Fetherston, C. (1998). Risk Factors for Lactation Mastitis. Journal Of Human Lactation, 101-109. /10.1177/089033449801400209.

Mannel, R., Martens, P. J., \& Walker, M. (2013). Core Curriculum for Lactation Consultant Practice. Boston, United States of America: Jones And Bartlett Publishers.

Biancuzzo, M. (1999). Maternal physical assessment and counseling. In: Breastfeeding the newborn. , (pp. 226-304). St. Louis: Mosby.

Tanguay, K. E., Mcbean, M. R., \& Jain, E. (1994). Nipple candidiasis among breastfeeding mothers. Case-control study of predisposing factors. Can Fam Physician, 1407-1413.

Departamento Científico de Aleitamento Materno. (2017). Doenças maternas infecciosas e amamentação: Guia prático de Atualização. Rio de Janeiro: Sociedade Brasileira de Pediatria.

(SAPS) Secretaria de Atenção Primária À Saúde. (2020). Protocolo de manejo clínico do Corona virus (COVID-19) na atenção primária a saúde. Brasilia: Ministério da Saúde.

Liebert, M. A. I. (2020). Coronavirus Treatment and Risk to Breastfeeding Women. Breastfeeding Medicine. New Rochelle.

Chen, H., Guo, J., Wang, C., Luo, F., Yu, X., Zhang, W., Li, J., Zhao, D., Xu, D., \& Gong, Q. (2020). Clinical characteristics and intrauterine vertical transmission potential of COVID-19 infection in nine pregnant women: a retrospective review of medical records. Lancet, 809-815.

Wang, L., Shi, Y., Xiao, T., Fu, J., Feng, X.; Mu, D., Feng, Qi, Hei, M., \& Hu, X. (2019). Chinese expert consensus on the perinatal and neonatal management for the prevention and control of the 2019 novel coronavirus infection (First edition). Annals Of Translational Medicine, 47-47. /10.21037/atm.2020.02.20.

Amounier, J. A., Moulin, Z. S., \& Xavier, C. C. (2004). Recomendações quanto à amamentação na vigência de infecção materna. J. Pediatr. (Rio J.), 181188.

De Miranda, V. S. G., Rech, R. S., Maahs, M. A. P., Berbert, M. C. B., \& De Almeida, S. T. (2020). Fonoaudiologia, amamentação e COVID-19: informações aos fonoaudiólogos. CoDAS. 